\title{
High D(-) lactic acid levels production by Sporolactobacillus nakayamae and an efficient purification
}

\author{
Susan Michelz Beitel ${ }^{1}$ - Daiane Cristina Sass ${ }^{1}$. Luciana Fontes Coelho ${ }^{1}$. \\ Jonas Contiero ${ }^{1}$
}

Received: 21 January 2016 / Accepted: 26 May 2016/Published online: 30 June 2016

(C) Springer-Verlag Berlin Heidelberg and the University of Milan 2016

\begin{abstract}
This study is the first to report the efficient production of $\mathrm{D}(-)$ lactic acid by a strain of Sporolactobacillus nakayamae utilizing inexpensive peanut flour as a nitrogen source and commercial sucrose as a carbon source. A $\mathrm{D}(-)$ lactic acid concentration of $112.93 \mathrm{~g} / \mathrm{L}$ was obtained by fermentation using $110.00 \mathrm{~g} / \mathrm{L}$ of commercial sucrose, $150.40 \mathrm{~g} /$ $\mathrm{L}$ of peanut flour, and $0.16 \mathrm{ml} / \mathrm{L}$ of Tween 80 . The optimal medium composition was determined using experimental design such as a Plackett-Burman, fractional factorial designs, and response surface methodology. The purification and recovery of $\mathrm{D}(-)$ lactic acid from the fermentation medium were performed using two purification techniques (filtration with activated carbon, followed by celite and cation resin exchange). This approach showed a high efficiency in protein and sugar removal as well in $\mathrm{D}(-)$ lactic acid recovery from the fermentation medium. Thus, the results indicate that S. nakayamae is a promising new $\mathrm{D}(-)$ lactic acid producer.
\end{abstract}

Electronic supplementary material The online version of this article (doi:10.1007/s13213-016-1224-4) contains supplementary material, which is available to authorized users.

Jonas Contiero

jconti@rc.unesp.br

1 Department of Biochemistry and Microbiology, Institute of Biological Sciences, UNESP- Univ. Estadual Paulista, Av. 24A 1515 CEP, 13506-900 Rio Claro, São Paulo, Brazil
Keywords D(-) Lactic acid · Isomers $\cdot$ Sporolactobacillus nakayamae $\cdot$ Purification $\cdot$ Submerged fermentation

\section{Introduction}

The production of lactic acid by microorganisms has gained a prime position in industry because it is cost effective and ecofriendly. Lactic acid is a versatile chemical with a wide variety of applications across a range of industries (John et al. 2009; Djukić-Vuković et al. 2012). Lactic acid can be produced by fermentation from different raw materials and through various technological means; additionally, it has versatile properties as a precursor for various chemicals and materials (Kim et al. 2006; Zhang et al. 2007; Hetényi et al. 2008; Dumbrepatil et al. 2008).

Approximately $40 \%$ of produced lactic acid is used in manufacturing polylactic acid (Bozell and Petersen 2010), which has recently been studied with great interest as a biodegradable polymer that can be used in the production of food packaging, plastic utensils, and plastic sheeting used for parts of computers, thereby replacing products made from petroleum (Ohara 2003; Coelho et al. 2011a, b). L(+) Lactic acid is used in the food industry to preserve human foodstuffs and is also utilized in the pharmaceutical and cosmetic industries (Li et al. 2004; Naveena et al. 2005; Wee et al. 2006a, b).

Some microorganisms can produce optically pure $\mathrm{L}(+)$ or $\mathrm{D}(-)$ lactic acid isomers via fermentation, while racemic DLlactic acid is produced via chemical synthesis (Hofvendahl and Hahn-Hägerdal 2000; Lima et al. 2010). In the literature, there are more studies involving L (+) lactic acid than there are for $\mathrm{D}(-)$ lactic acid production, and additionally, the production yield of $\mathrm{D}(-)$ lactic acid is lower than that of $\mathrm{L}(+)$ lactic acid (Wang et al. 2011). 
Design experiments have been frequently used for optimizing media to improve lactic acid production (Chauhan et al. 2006; Mel et al. 2008). Methods such as factorial design and response surface methodology provide powerful and efficient ways to optimize cultivation and procedures using a reduced number of experiments (Mandenius and Brundin 2008).

The quality of the lactic acid from fermentation media is closely related to recovery and purification methodologies (González et al. 2006). Typically, lactic acid for use in polymers, pharmaceuticals, or food derivatives requires further purification steps; however, the inclusion of these steps is responsible for the high cost of lactic acid obtained by fermentation (Timbuntam et al. 2008). Thus, to reduce costs and solve environmental problems, many studies of the recovery and purification of lactic acid from fermentation media have been conducted using different separation techniques (Marinova et al. 2004; González et al. 2006; Timbuntam et al. 2008).

The present study reports on the highly efficient production of $\mathrm{D}(-)$ lactic acid by $S$. nakayamae using peanut flour as a nitrogen source to reduce the production cost. Fermentation conditions were optimized through experimental design. Additionally, a new methodology for the recovery and purification of $\mathrm{D}(-)$ lactic acid from the fermentation medium by filtration through activated carbon and Celite, followed by cation exchange chromatography is presented.

\section{Materials and Methods}

\section{Bacteria strain and culture conditions}

No specific permissions were required for these locations because this microorganism was collected within the university. S. nakayamae, a homofermentative lactic acid bacterium that produces $\mathrm{D}(-)$ lactic acid with high optical purity, was used in this study. This microorganism was isolated from the rhizosphere of Desmodium adscendens collected in the state of São Paulo (Brazil). The strain was stored in GYP medium with $20 \%$ (by volume) glycerol at $-80{ }^{\circ} \mathrm{C}$. GYP medium is composed of $2 \%$ glucose, $1 \%$ yeast extract, $1 \%$ peptone, $1 \%$ sodium acetate, and $0.5 \%$ (v/v) salt solution, which was comprised of $4 \% \mathrm{MgSO}_{4} \cdot 7 \mathrm{H}_{2} \mathrm{O}, 0.16 \% \mathrm{MnSO}_{4} \cdot 4 \mathrm{H}_{2} \mathrm{O}, 0.2 \%$ $\mathrm{FeSO}_{4} .7 \mathrm{H}_{2} \mathrm{O}$ and $0.2 \% \mathrm{NaCl} ; \mathrm{pH} 7.0$.

\section{Inoculum and shake-flask fermentation}

Inoculum was prepared from activated culture grown on GYP medium incubated at $35 \pm 1{ }^{\circ} \mathrm{C}$ under stationary conditions until the $\mathrm{OD}_{600}$ reached 2.5 (approximately 18-20 h). Experiments were performed in $125-\mathrm{mL}$ flasks containing $18 \mathrm{~mL}$ of GYP medium at $\mathrm{pH} 7.0$ and inoculated with $2 \mathrm{~mL}$ of the seed culture ( $10 \%$ inoculum). To avoid a $\mathrm{pH}$ decrease because of lactic acid production, $50 \mathrm{~g} / \mathrm{L}$ of $\mathrm{CaCO}_{3}$ was added to each flask. The temperature was kept at $35^{\circ} \mathrm{C}$. The cultures were incubated at different conditions, as described below. All experiments were carried out in duplicate to verify their reproducibility, and the results are expressed as mean values. The fermentation samples were centrifuged at $7000 \times \mathrm{g}$ for $15 \mathrm{mi}$ nutes. The resulting supernatant was filtered through a $0.22-\mu \mathrm{m}$ membrane and was then used to determine the concentration of residual sugar and $\mathrm{D}(-)$ lactic acid .

\section{Lactic acid production on different carbon and nitrogen sources}

Lactic acid production was studied with different substrates as carbon and nitrogen sources based in GYP medium, with incubation for 48 hours at $35{ }^{\circ} \mathrm{C}$ under shaker conditions at $150 \mathrm{rpm}$.

After the sources that induced the highest lactic acid levels were selected, several concentrations of the carbon and nitrogen sources were evaluated using the experimental designs described below.

\section{Experimental designs}

Screening of significant nutritional components of lactic acid production using the Plackett-Burman Experimental Design (PBED)

The PBED was employed for screening and identifying the significance of eight parameters for $\mathrm{D}(-)$ lactic acid production. The GYP medium was modified to evaluate the influence of different nutritional components on lactic acid production. Each factor was tested at two levels (coded): a high level $(+1)$ and a low level $(-1)$ (Table 1), and four central points were screened

Table 1 Variables and their levels in lactic acid production under a PBED

\begin{tabular}{|c|c|c|c|c|}
\hline \multirow[t]{2}{*}{ Variable } & \multicolumn{2}{|c|}{ Code } & \multicolumn{2}{|c|}{ Levels } \\
\hline & & Low $(-1)$ & 0 & $\operatorname{High}(+1)$ \\
\hline Tween80 (ml/L) & $\mathrm{X}_{1}$ & 0 & 0.5 & 1 \\
\hline $\mathrm{MnSO}_{4}(\mathrm{~g} / \mathrm{L})$ & $\mathrm{X}_{2}$ & 0 & 0.05 & 0.1 \\
\hline $\mathrm{FeSO}_{4}(\mathrm{~g} / \mathrm{L})$ & $\mathrm{X}_{3}$ & 0 & 0.05 & 0.1 \\
\hline $\mathrm{NaCl}(\mathrm{g} / \mathrm{L})$ & $\mathrm{X}_{4}$ & 0 & 0.05 & 0.1 \\
\hline $\mathrm{MgSO}_{4}(\mathrm{~g} / \mathrm{L})$ & $\mathrm{X}_{5}$ & 0 & 1 & 2 \\
\hline Peanut flour $(\mathrm{g} / \mathrm{L})$ & $\mathrm{X}_{6}$ & 40 & 60 & 80 \\
\hline Sodium acetate $(\mathrm{g} / \mathrm{L})$ & $\mathrm{X}_{7}$ & 0 & 5 & 10 \\
\hline Commercial sucrose $(\mathrm{g} / \mathrm{L})$ & $\mathrm{X}_{8}$ & 80 & 115 & 150 \\
\hline
\end{tabular}

Samples were incubated at a temperature of $35 \pm 1^{\circ} \mathrm{C}$ for 48 hours at $100 \mathrm{rpm}$. A Fractionated Factorial Design (FFD) was performed according the variables that significantly influenced the production of lactic acid 
by running 16 experiments. The factors that were significant at the $5 \%$ level $(P<0.05)$ from the regression analysis were considered to have a high impact on lactic acid production.

\section{Fractional factorial designs}

Five variables were studied in a $2^{5-1} \mathrm{FFD}$ to estimate their effect on lactic acid production. A total of 19 experiments were carried out, with 16 experiments related to the design structure and three repetitions at the central point. The two extreme levels are denoted by minus one (lower level) and plus one (higher level), as shown in Table 2.

A new approach of GYP salts was evaluated, and it was added to the solution at certain concentrations. Once peanut flour was established as a nitrogen source, the influence of B vitamins on the production of lactic acid was examined. The fermentation was carried out under shaker conditions $(100 \mathrm{rpm})$ at $35^{\circ} \mathrm{C}$ for 48 hours. After incubation, the cultures were processed and quantitatively assayed for lactic acid and residual sugar production.

\section{Response Surface Methodology (RSM)}

The RSM was applied to evaluate the interaction of variables and then used to find the optimum concentration of the medium components that greatly affect $\mathrm{D}(-)$ lactic acid production (Table 3). To study the influence of commercial sucrose, peanut flour, and Tween 80 on the production of lactic acid by S. nakayamae, an RSM was used, with four replicates at the center, totaling 18 experiments.

The flasks were incubated for 72 hours at $35{ }^{\circ} \mathrm{C}$ under shaker conditions at $100 \mathrm{rpm}$. Lactic acid and residual sugar were quantified.

\section{Experimental validation}

To validate the optimum values selected by the response surface analysis, two conditions were tested. The concentrations utilized were: $110.00 \mathrm{~g} / \mathrm{L}$ of commercial sucrose, 150.40 of

Table 2 Design matrix for the fractional $2^{5-1}$ factorial experiments, used to study the influence of 5 factors on $S$. nakayamae $\mathrm{D}(-)$ lactic acid production

\begin{tabular}{|c|c|c|c|c|}
\hline \multirow[t]{2}{*}{ Variable } & \multicolumn{2}{|c|}{ Code } & \multicolumn{2}{|c|}{ Levels } \\
\hline & & Low $(-1)$ & 0 & $\operatorname{High}(+1)$ \\
\hline Commercial sucrose $(\mathrm{g} / \mathrm{L})$ & $\mathrm{X}_{1}$ & 80 & 100 & 120 \\
\hline Peanut flour (g/L) & $\mathrm{X}_{2}$ & 60 & 80 & 100 \\
\hline Tween $80(\mathrm{ml} / \mathrm{L})$ & $\mathrm{X}_{3}$ & 0.5 & 1 & 1.5 \\
\hline GYP Salts solution $(\mathrm{g} / \mathrm{L})$ & $\mathrm{X}_{4}$ & 0 & 2.5 & 5 \\
\hline Vitamins $(\mathrm{ml} / \mathrm{L})$ & $\mathrm{X}_{5}$ & 0 & 5 & 10 \\
\hline
\end{tabular}

Table 3 Variables and their levels of lactic acid production under an RSM

\begin{tabular}{lllllll}
\hline Variable & \multicolumn{2}{l}{ Levels } \\
\cline { 2 - 7 } & & $-1,68$ & -1 & 0 & +1 & $+1,68$ \\
\hline Commercial sucrose $(\mathrm{g} / \mathrm{L})$ & $\mathrm{X}_{1}$ & 76,40 & 90 & 110 & 130 & 143,60 \\
Peanut Flour $(\mathrm{g} / \mathrm{L})$ & $\mathrm{X}_{2}$ & 49,60 & 70 & 100 & 130 & 150,40 \\
Tween $80(\mathrm{ml} / \mathrm{L})$ & $\mathrm{X}_{3}$ & 0,16 & 0,5 & 1,00 & 1,5 & 1,84 \\
\hline
\end{tabular}

peanut flour, and two different concentrations of Tween 80 , $1.00 \mathrm{ml} / \mathrm{L}$ and $0.16 \mathrm{ml} / \mathrm{L}$.

The fermentation was carried out under shaker conditions (100 rpm) at $35{ }^{\circ} \mathrm{C}$ for 72 hours. Each condition was tested five times, and the results are expressed as the mean values.

\section{Purification and recovery of $\mathrm{D}(-)$ lactic acid}

The fermentation medium was centrifuged at $7000 \times g$ at $20{ }^{\circ} \mathrm{C}$ for $10 \mathrm{~min}$, and the $\mathrm{pH}$ was adjusted to 5.0. Then, $60 \mathrm{ml}$ of the medium $(88.27 \mathrm{~g} / \mathrm{L} \mathrm{D}(-)$ lactic acid and $13.50 \mathrm{~g} / \mathrm{L}$ of sugar) was vacuum filtered through a sintered plate funnel $(3.50 \mathrm{~cm}$ diameter and $5.00 \mathrm{~cm}$ high) containing $1 \mathrm{~cm}$ of activated carbon and $1 \mathrm{~cm}$ of Celite. The filtrate was filtered through activated carbon and Celite twice, then passed through a cation exchange column (Ambertile IRA 120 hydrogen forms), and filtered through a $0.22-\mu \mathrm{m}$ membrane. Then, the final solution was used to determine the lactic acid, sugar, and protein concentrations. The total protein concentration was determined by the Lowry method (Peterson 1977).

The lactic acid recovery yield was calculated as follow: lactic acid recovery yield $(\%)=($ final mass $(\mathrm{g}) /$ initial mass (g) $) \times 100$.

The sugar removal was calculated using this formula: sugar removal $(\%)=(($ initial mass $(\mathrm{g})-$ final mass $(\mathrm{g})) /$ initial mass $(\mathrm{g})) \times 100$.

\section{Analytical techniques}

The concentrations of sucrose, lactose, and lactic acid were determined by high-performance liquid chromatography (HPLC) using a column Rezex ROA $300 \mathrm{~mm} \times 7.8 \mathrm{~m}$ (Phenomenex, USA) and a differential refracting index detector (Shimadzu Ultra Fast Liquid Chromatograph, Japan). The mobile phase $\left(0.005 \mathrm{M} \mathrm{H}_{2} \mathrm{SO}_{4}\right)$ was fed at a flow rate of $0.6 \mathrm{~mL} / \mathrm{min}$, and the temperature was kept at $65^{\circ} \mathrm{C}$.

In the end of the optimization process of $\mathrm{D}(-)$ lactic acid production, the optical purity of lactic acid produced was determined by HPLC using a Chirex 3126 phenomenex $(150 \times 4.6 \mathrm{~mm})$ column with $1 \mathrm{mM}$ of $\mathrm{CuSO} 4$ as the mobile phase at $1 \mathrm{~mL} / \mathrm{min}\left(26^{\circ} \mathrm{C}\right)$. 


\section{Statistical analysis}

The experimental design and the results analysis in all experimental designs were determined using STATISTICA 7 (StatSoft, Tulsa, USA).

\section{Results and discussion}

\section{Influence of carbon sources}

$\mathrm{D}(-)$ Lactic acid production by S. nakayamae under the influence of four inexpensive carbon sources was studied (Table 4).

The carbon source that induced the highest lactic acid production was commercial sucrose, producing $59.50 \mathrm{~g} / \mathrm{L}$ of lactic acid. S. nakayamae was also able to produce lactic acid in the presence of sugarcane juice, yielding $53.80 \mathrm{~g} / \mathrm{L}$ of lactic acid. In the presence of whey and molasses, low levels of lactic acid were produced compared to those of the cultures grown with commercial sucrose and sugarcane juice. It may be that growing the cultures with molasses produced low levels of lactic acid because of the heavy metals (iron, zinc, copper, manganese) found in this substrate, which may inhibit cell growth and inactivate the enzymes involved in final product conversion. However, in previous studies, it was shown that $\mathrm{L}(+)$ lactic acid production by Enterococcus faecalis from molasses reached a maximum concentration of $134.9 \mathrm{~g} / \mathrm{L}$, with a maximum productivity of $4.3 \mathrm{~g} / \mathrm{Lh}$ (Wee et al. 2006a, b). In the presence of whey, the low level of $\mathrm{D}(-)$ lactic acid production should be caused by the inability of $S$. nakayamae to metabolize the lactose, which is the sugar present in this residue, as reported before by Sanders et al. 2003 when referring to the other species of the genus Sporolactobacillus. In contrast, in a previous study, it was reported that $52.5 \mathrm{~g} / \mathrm{L}$ of lactic acid was produced from whey by Lactobacillus helveticus (Ghaly et al. 2004).

Among the sources tested, commercial sucrose was selected. Although sugarcane juice was also capable of inducing lactic acid production, this substrate is less interesting in regards to further purification.

\section{Influence of nitrogen sources}

Different sources of nitrogen were also studied: corn-steep liquor, Proflo, peanut flour, soybean flour, and urea. The effects of each of these nitrogen sources on lactic acid production are shown in Table 5.

The nitrogen source that induced the highest lactic acid production was peanut flour, corresponding to $57.00 \mathrm{~g} / \mathrm{L}$ of lactic acid. Moreover, Proflo, induced the production of $52.2 \mathrm{~g} / \mathrm{L}$ of $\mathrm{D}(-)$ lactic acid, and a yield of $0.70 \mathrm{~g}$ of lactic $\mathrm{acid} / \mathrm{g}$ of Proflo. Thus, it was the second most efficient nitrogen source in the production of lactic acid by S. nakayamae. This source presents some vitamins on composition, which possibly have a role on this fermentation. Peanut flour and soybean flour have several minerals in their composition (calcium, iron, mMagnesium, manganese, and sodium), which can act as enzyme cofactors. Similar to this study, it has been previously shown that Bacillus sp. and Sporolactobacillus sp. CASD produce high levels of $\mathrm{L}(+)$ and $\mathrm{D}(-)$ lactic acid, respectively, using peanut flour as their sole nitrogen source (Meng et al. 2012; Wang et al. 2011).

Moreover, in another previous study, it was reported that Lactobacillus sp. produced $41.42 \mathrm{~g} / \mathrm{L}$ of $\mathrm{D}(-)$ lactic acid using corn step liquor and yeast autolysate (Lima et al. 2009). In the present study, when only corn step liquor was used as a nitrogen source, the lactic acid production was not as efficient, yielding $13.26 \mathrm{~g} / \mathrm{L}$ of $\mathrm{D}(-)$ lactic acid . Furthermore, it left a high concentration of residual sugar $(70.00 \mathrm{~g} / \mathrm{L})$.

Because the nitrogen source accounts for approximately $38 \%$ of the total process cost during lactic acid production (Altaf et al. 2007), the use of wastes and inexpensive nitrogen sources in fermentation medium would reduce these costs.

\section{Experimental designs}

\section{Plackett-Burman Experimental Design}

The PBED is an efficient screening method for identifying the active factors of an experiment using as few experimental runs as possible.
Table 4 Influence of carbon sources on S. nakayamae lactic acid production, productivity, and yield

\begin{tabular}{llllll}
\hline Carbon sources & Carbohydrates & $\begin{array}{l}\text { D(-) Lactic acid } \\
\text { Production }(\mathrm{g} / \mathrm{L})\end{array}$ & $\begin{array}{l}\text { Productivity } \\
(\mathrm{g} / \mathrm{Lh})\end{array}$ & $\begin{array}{l}\text { Yield Yp/s } \\
(\mathrm{g} / \mathrm{g})\end{array}$ & $\begin{array}{l}\text { Residual sugar } \\
(\mathrm{g} / \mathrm{L})\end{array}$ \\
\hline Molasses & $46,9(\mathrm{~g} / 100 \mathrm{~mL})^{\mathrm{a}}$ & 1.06 & 0.02 & 0.12 & 91.40 \\
Commercial sucrose & $100(\mathrm{~g} / 100 \mathrm{~g})^{\mathrm{a}}$ & 59.50 & 1.23 & 0.69 & 14.80 \\
Sugarcane juice & $19.95(\mathrm{~g} / 100 \mathrm{~mL})^{\mathrm{a}}$ & 53.80 & 1,12 & 0.66 & 19.20 \\
Whey & $76.59(\mathrm{~g} / 100 \mathrm{~g})^{\mathrm{b}}$ & 1.26 & 0.02 & 0.11 & 88.57 \\
\hline
\end{tabular}

Culture conditions: GYP medium with $100 \mathrm{~g} / \mathrm{L}$ of carbon source, $5 \%$ of $\mathrm{CaCO}_{3}$, at $35^{\circ} \mathrm{C}$ under shaker conditions at $150 \mathrm{rpm}$, for $48 \mathrm{~h}$, with an initial $\mathrm{pH}$ of 7.0. Type of carbohydrate: a)sucrose; b) lactose 
Table 5 Influence of nitrogen sources on S. nakayamae lactic acid production, productivity, and yield

\begin{tabular}{llllll}
\hline Nitrogen sources & $\mathrm{N} \%$ & $\begin{array}{l}\mathrm{D}(-) \text { Lactic acid } \\
\text { Production }(\mathrm{g} / \mathrm{L})\end{array}$ & $\begin{array}{l}\text { Productivity } \\
(\mathrm{g} / \mathrm{Lh})\end{array}$ & $\begin{array}{l}\text { Yield Yp/s } \\
(\mathrm{g} / \mathrm{g})\end{array}$ & $\begin{array}{l}\text { Residual sugar } \\
(\mathrm{g} / \mathrm{L})\end{array}$ \\
\hline Proflo & 11.15 & 52.20 & 1.09 & 0.71 & 26.43 \\
Corn step liquor & 4,69 & 13.26 & 0.28 & 0.44 & 70.00 \\
Urea & 46.62 & 38.40 & 0.80 & 0.78 & 51.00 \\
Soybean flour & 6.40 & 41.28 & 0.86 & 0.60 & 30.81 \\
Peanut flour & 7.63 & 57.00 & 1.19 & 0.72 & 21.2 \\
\hline
\end{tabular}

Culture conditions: GYP medium with $100 \mathrm{~g} / \mathrm{L}$ of commercial sucrose, $5 \%$ of $\mathrm{CaCO}_{3}$, at $35^{\circ} \mathrm{C}$ under shaker conditions at $150 \mathrm{rpm}$, for $48 \mathrm{~h}$, at an initial of $\mathrm{pH}$ 7.0. The nitrogen content of all media was $15.25 \%$,
The matrix (coded values) of the 16 experiments with eight variables and the respective results are shown in Table 6. After 48 hours of fermentations, the maximum level of lactic acid production was $58.90 \mathrm{~g} / \mathrm{L}$ (run 7).

The Pareto graph implied that the variables $\mathrm{MgSO}_{4}$, peanut flour, Tween 80, and commercial sucrose influenced the fermentation process significantly at a $95 \%$ confidence level. $\mathrm{MgSO}_{4}$ and commercial sucrose had negative coefficients, while peanut flour and Tween 80 showed positive coefficients (Fig. 1a).

Kitouni and Oulmi (2013) using PBED reported that the use of manganese, magnesium, and iron sulfates as sources of oligoelements appears to have no significant effect on the lactic acid production by Lactobacillus bulgaricus attc 11842 grown on whey.

Once the peanut flour presents high lipid concentration in the composition $(51.77 \mathrm{~g} / 100 \mathrm{~g})$, the surfactant property of
Tween 80 can interact with lipids, improving the solubility of the nutrients found in peanut flour. Tween 80 may assist in nutrient absorption by microorganisms, as well as product liberation by facilitating transport via the cell membrane of the microorganism. Conversely, Coelho et al. 2011a, b reported that Tween 80 had a significant positive effect on lactic acid production by Lactobacillus plantarum LMISM6.

The negative effect of commercial sucrose is probably related to the high concentration used, which could inhibit the lactic acid production. Therefore, the components selected for the next experiment were peanut flour, commercial sucrose, and Tween 80 .

Several studies reported the use of PBED successfully employed to screen the significance components in culture media, in order to improve the lactic acid production (Wang et al. 2015; Qin et al. 2009; Chauhan et al. 2007). Gowdhaman et al. (2012) using PBED was able to select three variables
Table 6 PBED with coded values and experimental results for lactic acid production, productivity, yield, and residual sugar concentration

\begin{tabular}{|c|c|c|c|c|c|c|c|c|c|c|c|c|}
\hline \multirow[t]{2}{*}{ Run } & \multicolumn{8}{|c|}{ Independent variables } & \multirow{2}{*}{$\begin{array}{l}\text { Lactic } \\
\text { acid } \\
\mathrm{g} / \mathrm{L}\end{array}$} & \multirow{2}{*}{$\begin{array}{l}\text { Productivity } \\
\mathrm{g} / \mathrm{L} / \mathrm{h}\end{array}$} & \multirow{2}{*}{$\begin{array}{l}\text { Yield Y } \\
\mathrm{p} / \mathrm{s} \\
\mathrm{g} / \mathrm{g}\end{array}$} & \multirow{2}{*}{$\begin{array}{l}\text { Residua } \\
\text { sugar } \\
\mathrm{g} / \mathrm{L}\end{array}$} \\
\hline & $\mathrm{X}_{1}$ & $\mathrm{X}_{2}$ & $\mathrm{X}_{3}$ & $\mathrm{X}_{4}$ & $\mathrm{X}_{5}$ & $\mathrm{X}_{6}$ & $\mathrm{X}_{7}$ & $\mathrm{X}_{8}$ & & & & \\
\hline 1 & 1 & -1 & 1 & -1 & -1 & -1 & 1 & 1 & 52.44 & 1.09 & 0.80 & 84.35 \\
\hline 2 & 1 & 1 & -1 & 1 & -1 & -1 & -1 & 1 & 44.40 & 0.92 & 0.69 & 86.02 \\
\hline 3 & -1 & 1 & 1 & -1 & 1 & -1 & -1 & -1 & 30.43 & 0.63 & 0.99 & 49.15 \\
\hline 4 & 1 & -1 & 1 & 1 & -1 & 1 & -1 & -1 & 55.85 & 1.16 & 0.98 & 22.92 \\
\hline 5 & 1 & 1 & -1 & 1 & 1 & -1 & 1 & -1 & 51.05 & 1.06 & 0.97 & 27.63 \\
\hline 6 & 1 & 1 & 1 & -1 & 1 & 1 & -1 & 1 & 45.78 & 0.95 & 0.78 & 91.09 \\
\hline 7 & -1 & 1 & 1 & 1 & -1 & 1 & 1 & -1 & 58.90 & 1.22 & 0.99 & 23.75 \\
\hline 8 & -1 & -1 & 1 & 1 & 1 & -1 & 1 & 1 & 15.64 & 0.32 & 0.76 & 133.72 \\
\hline 9 & -1 & -1 & -1 & 1 & 1 & 1 & -1 & 1 & 40.96 & 0.85 & 0.77 & 96.73 \\
\hline 10 & 1 & -1 & -1 & -1 & 1 & 1 & 1 & -1 & 54.73 & 1.14 & 0.98 & 24.42 \\
\hline 11 & -1 & 1 & -1 & -1 & -1 & 1 & 1 & 1 & 48.70 & 1.01 & 0.40 & 98.93 \\
\hline 12 & -1 & -1 & -1 & -1 & -1 & -1 & -1 & -1 & 51.73 & 1.08 & 0.95 & 25.42 \\
\hline 13 & 0 & 0 & 0 & 0 & 0 & 0 & 0 & 0 & 51.19 & 1.07 & 0.96 & 61.61 \\
\hline 14 & 0 & 0 & 0 & 0 & 0 & 0 & 0 & 0 & 46.38 & 0.97 & 0.76 & 53.70 \\
\hline 15 & 0 & 0 & 0 & 0 & 0 & 0 & 0 & 0 & 50.25 & 1.05 & 0.78 & 50.60 \\
\hline 16 & 0 & 0 & 0 & 0 & 0 & 0 & 0 & 0 & 51.59 & 1.07 & 0.94 & 59.97 \\
\hline
\end{tabular}

$\mathrm{X}_{1}=$ Tween80. $\mathrm{X}_{2}=\mathrm{MnSO}_{4} \cdot \mathrm{X}_{3}=\mathrm{FeSO}_{4} \cdot \mathrm{X}_{4}=\mathrm{NaCl} . \mathrm{X}_{5}=\mathrm{MgSO}_{4} \cdot \mathrm{X}_{6}=$ Peanut flour. $\mathrm{X}_{7}=$ Sodium acetate $\mathrm{X}_{8}=$ Commercial sucrose. Culture conditions: $35^{\circ} \mathrm{C}$, initial $\mathrm{pH}$ of 7.0 neutralized by $5 \% \mathrm{CaCO}_{3}, 100 \mathrm{rpm}$ of agitation, $10 \%$ inoculum. Fermentation was carried out for 48 hours 
a

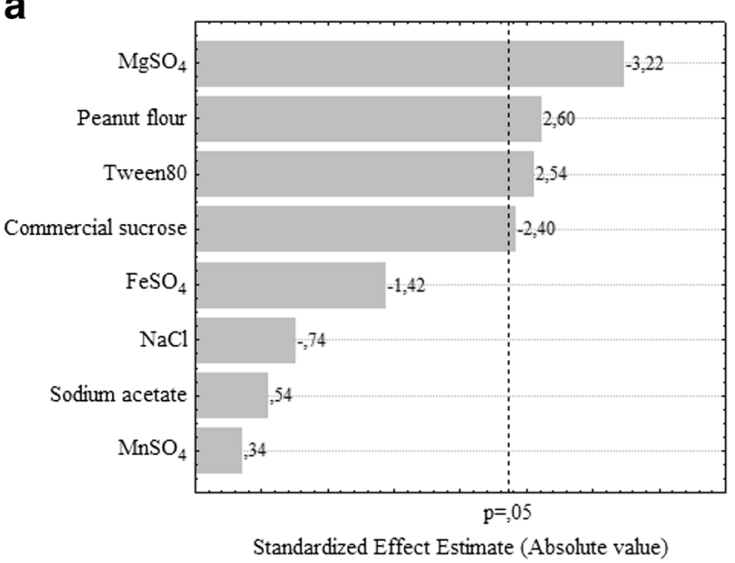

Fig. 1 Pareto graph for $\mathrm{D}(-)$ lactic acid production. a) PBED; b) FFD

namely substrate concentration, moisture content, and yeast concentration that have statistically significant effect on lactic acid yield by Lactobacillus plantarum MTCC 6161 in solidstate fermentation. Chauhan et al. 2006, studying optimization of lactic acid production using date juice, reported that among the fifteen variables (date juice, peptone, beef extract, yeast extract, $\mathrm{K} 2 \mathrm{HPO} 4, \mathrm{KH} 2 \mathrm{PO} 4, \mathrm{MgSO} 4 \cdot 7 \mathrm{H} 2 \mathrm{O}, \mathrm{MnSO} 4 \cdot \mathrm{H} 2 \mathrm{O}$, sodium acetate, sodium sulfate, tri-sodium citrate, sodium succinate, tween-80, F,eSO4 and $\mathrm{NaCl}$ ), significant components were screened out using PBED. This experiment b

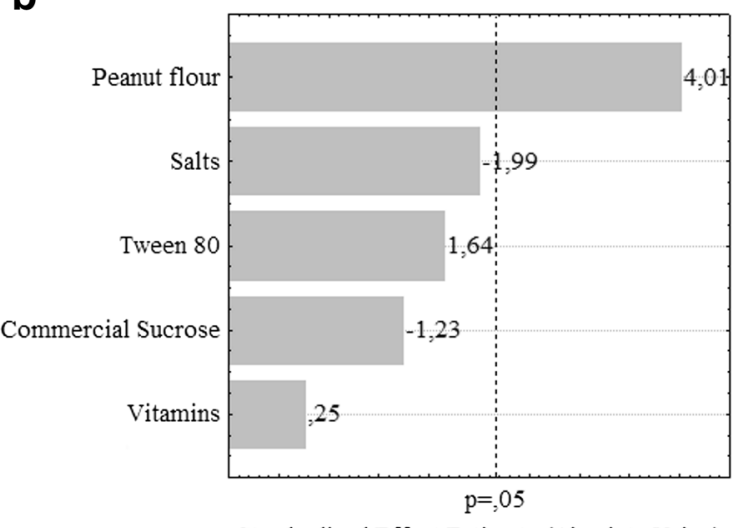

Standardized Effect Estimate (Absolute Value)

suggested four components, date juice, peptone, K2HPO4, and sodium acetate, as having significant effects on lactic acid production by Lactobacillus sp. KCP01.

\section{Fractional factorial designs (FFD)}

In this study, a $2^{5-2}$ FFD was used to determine the significant factors of five media components. The 19 runs and the results of the response FFD are presented in Table 7.
Table 7 Fractional factorial design with coded and experimental results for lactic acid production, productivity, yield, and residual sugar concentration

\begin{tabular}{|c|c|c|c|c|c|c|c|c|c|}
\hline \multirow[t]{2}{*}{ Run } & \multicolumn{5}{|c|}{ Independent variables } & \multirow{2}{*}{$\begin{array}{l}\text { Lactic acid } \\
\mathrm{g} / \mathrm{L}\end{array}$} & \multirow{2}{*}{$\begin{array}{l}\text { Productivity } \\
\text { g/Lh }\end{array}$} & \multirow{2}{*}{$\begin{array}{l}\text { Yield Yp/s } \\
\mathrm{g} / \mathrm{g}\end{array}$} & \multirow{2}{*}{$\begin{array}{l}\text { Residual sugar } \\
\text { g/L }\end{array}$} \\
\hline & $\mathrm{X}_{1}$ & $\mathrm{X}_{2}$ & $X_{3}$ & $\mathrm{X}_{4}$ & $\mathrm{X}_{5}$ & & & & \\
\hline 1 & -1 & -1 & -1 & -1 & 1 & 48.49 & 1.01 & 1.20 & 39.70 \\
\hline 2 & 1 & -1 & -1 & -1 & -1 & 41.76 & 0.87 & 0.48 & 33.15 \\
\hline 3 & -1 & 1 & -1 & -1 & -1 & 47.82 & 1.00 & 0.67 & 8.70 \\
\hline 4 & 1 & 1 & -1 & -1 & 1 & 46.46 & 0.97 & 0.70 & 53.74 \\
\hline 5 & -1 & -1 & 1 & -1 & -1 & 46.24 & 0.96 & 0.62 & 5.35 \\
\hline 6 & 1 & -1 & 1 & -1 & 1 & 44.35 & 0.92 & 0.85 & 67.86 \\
\hline 7 & -1 & 1 & 1 & -1 & 1 & 49.02 & 1.02 & 0.97 & 29.21 \\
\hline 8 & 1 & 1 & 1 & -1 & -1 & 51.92 & 1.08 & 0.87 & 60.04 \\
\hline 9 & -1 & -1 & -1 & 1 & -1 & 42.79 & 0.89 & 0.99 & 36.85 \\
\hline 10 & 1 & -1 & -1 & 1 & 1 & 43.05 & 0.90 & 0.80 & 66.22 \\
\hline 11 & -1 & 1 & -1 & 1 & 1 & 46.87 & 0.98 & 1.04 & 35.08 \\
\hline 12 & 1 & 1 & -1 & 1 & -1 & 44.01 & 0.92 & 0.83 & 66.79 \\
\hline 13 & -1 & -1 & 1 & 1 & 1 & 42.16 & 0.88 & 1.01 & 38.08 \\
\hline 14 & 1 & -1 & 1 & 1 & -1 & 42.79 & 0.89 & 0.80 & 66.63 \\
\hline 15 & -1 & 1 & 1 & 1 & -1 & 49.59 & 1.03 & 0.98 & 29.53 \\
\hline 16 & 1 & 1 & 1 & 1 & 1 & 48.59 & 1.01 & 0.98 & 70.22 \\
\hline 17 & 0 & 0 & 0 & 0 & 0 & 43.15 & 0.90 & 0.85 & 49.41 \\
\hline 18 & 0 & 0 & 0 & 0 & 0 & 44.205 & 0.92 & 0.89 & 50.13 \\
\hline 19 & 0 & 0 & 0 & 0 & 0 & 44.465 & 0.93 & 0.86 & 48.52 \\
\hline
\end{tabular}

$\mathrm{X}_{1}=$ Commercial sucrose $\mathrm{X}_{2}=$ Peanut flour. $\mathrm{X}_{3}=$ Tween $80 . \mathrm{X}_{4}=$ Salt solution. $\mathrm{X}_{5}=$ Vitamins. Culture conditions: $35^{\circ} \mathrm{C}$, initial pH 7.0 neutralized by $5 \% \mathrm{CaCO}_{3}, 100 \mathrm{rpm}$ of agitation, $10 \%$ inoculum. Fermentation was carried out for 48 hours 
Table 8 RSM design with coded values and experimental results for lactic acid production, productivity, yield, and residual sugar concentration

\begin{tabular}{|c|c|c|c|c|c|c|c|}
\hline \multirow[t]{2}{*}{ Run } & \multicolumn{3}{|c|}{ Independent variables } & \multirow{2}{*}{$\begin{array}{l}\text { Lactic acid } \\
\mathrm{g} / \mathrm{L}\end{array}$} & \multirow{2}{*}{$\begin{array}{l}\text { Productivity } \\
\text { g/Lh }\end{array}$} & \multirow{2}{*}{$\begin{array}{l}\text { Yield Y p/s } \\
\mathrm{g} / \mathrm{g}\end{array}$} & \multirow{2}{*}{$\begin{array}{l}\text { Residual sugar } \\
\mathrm{g} / \mathrm{L}\end{array}$} \\
\hline & $\mathrm{X}_{1}$ & $\mathrm{X}_{2}$ & $\mathrm{X}_{3}$ & & & & \\
\hline 1 & -1 & -1 & -1 & 78.10 & 1.08 & 0.88 & 15.20 \\
\hline 2 & 1 & -1 & -1 & 85.48 & 1.19 & 0.89 & 54.97 \\
\hline 3 & -1 & 1 & -1 & 81.67 & 1.13 & 0.79 & 9.95 \\
\hline 4 & 1 & 1 & -1 & 99.46 & 1.38 & 0.85 & 22.85 \\
\hline 5 & -1 & -1 & 1 & 83.77 & 1.16 & 0.92 & 9.89 \\
\hline 6 & 1 & -1 & 1 & 96.18 & 1.34 & 0.86 & 28.32 \\
\hline 7 & -1 & 1 & 1 & 78.81 & 1.09 & 0.91 & 6.80 \\
\hline 8 & 1 & 1 & 1 & 101.99 & 1.42 & 0.91 & 26.13 \\
\hline 9 & $-1,68$ & 0 & 0 & 82.40 & 1.14 & 0.95 & 5.39 \\
\hline 10 & 1,68 & 0 & 0 & 88.68 & 1.23 & 0.79 & 41.50 \\
\hline 11 & 0 & $-1,68$ & 0 & 88.53 & 1.23 & 0.91 & 23.80 \\
\hline 12 & 0 & 1,68 & 0 & 99.99 & 1.39 & 0.86 & 10.24 \\
\hline 13 & 0 & 0 & $-1,68$ & 93.47 & 1.30 & 0.84 & 16.24 \\
\hline 14 & 0 & 0 & 1,68 & 93.11 & 1.29 & 0.84 & 17.92 \\
\hline 15 & 0 & 0 & 0 & 93.53 & 1.30 & 0.88 & 20.88 \\
\hline 16 & 0 & 0 & 0 & 91.60 & 1.27 & 0.84 & 17.80 \\
\hline 17 & 0 & 0 & 0 & 88.80 & 1.23 & 0.85 & 22.66 \\
\hline 18 & 0 & 0 & 0 & 92.02 & 1.28 & 0.85 & 19.12 \\
\hline
\end{tabular}

$\mathrm{X} 1=$ Commercial sucrose, $\mathrm{X} 2=$ Peanut flour, $\mathrm{X} 3$ Tween 80 . Culture conditions: $35^{\circ} \mathrm{C}$, Initial $\mathrm{pH} 7.0$ neutralized by $5 \% \mathrm{CaCO}_{3}, 100 \mathrm{rpm}$ of agitation, $10 \%$ inoculum. Fermentation was carried out for 72 hours
The highest lactic acid concentration was identified on run $8(52.92 \mathrm{~g} / \mathrm{L})$. This run contained the highest concentrations of carbon and nitrogen sources and contained no salts or vitamins; however, the level of residual sugar found in this experiment was high $(60.04 \mathrm{~g} / \mathrm{L})$.

After 48 hours of fermentation, the peanut flour had a positive and significant effect on $\mathrm{D}(-)$ lactic acid production (Fig. 1b).

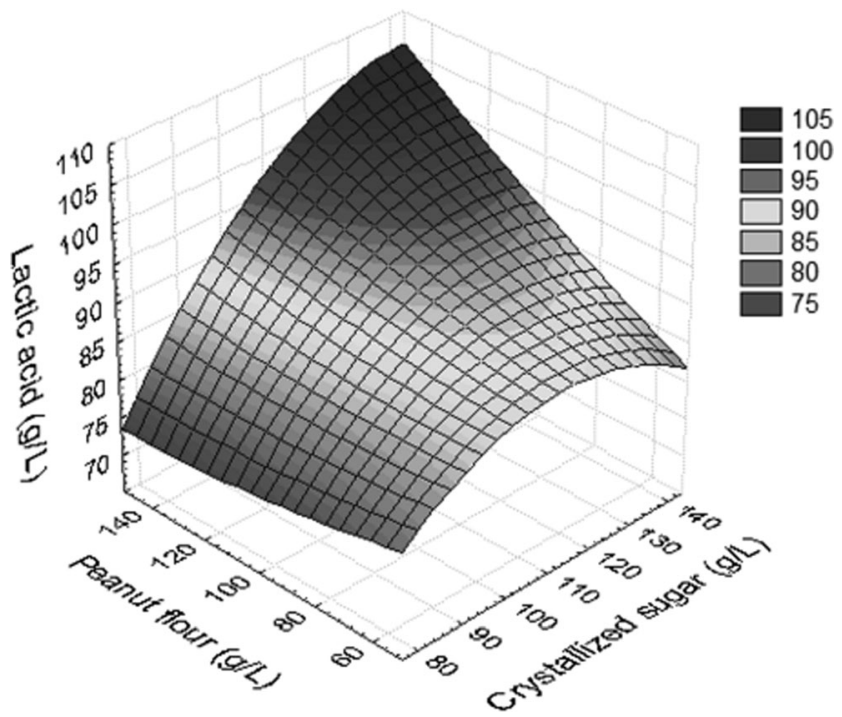

Fig. 2 Response surface for lactic acid production by $S$. nakayamae showing the interaction between peanut flour and commercial sucrose
The commercial sucrose and salts, despite being presented as not significantly influential, had negative effects on lactic acid production. This negative effect may be associated with the amount of carbohydrates and mineral salts that already exist in peanut flour, causing a high concentration of these components on the culture media. As previously mentioned, the negative effect of commercial sucrose is related to product inhibition mediated by high substrate concentration. Different

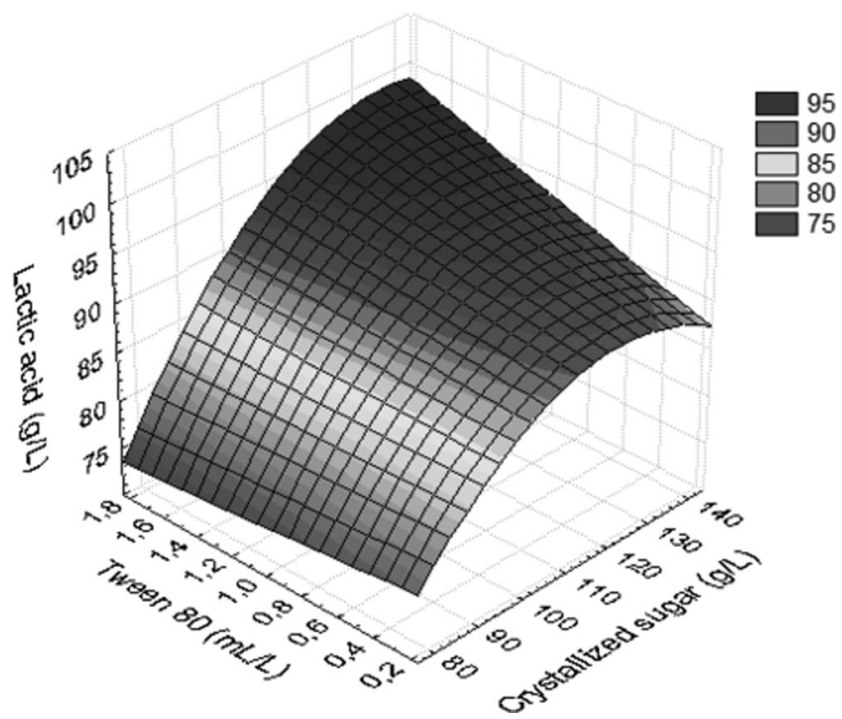

Fig. 3 Response surface for lactic acid production by S. nakayamae showing the interaction between Tween 80 and commercial sucrose 


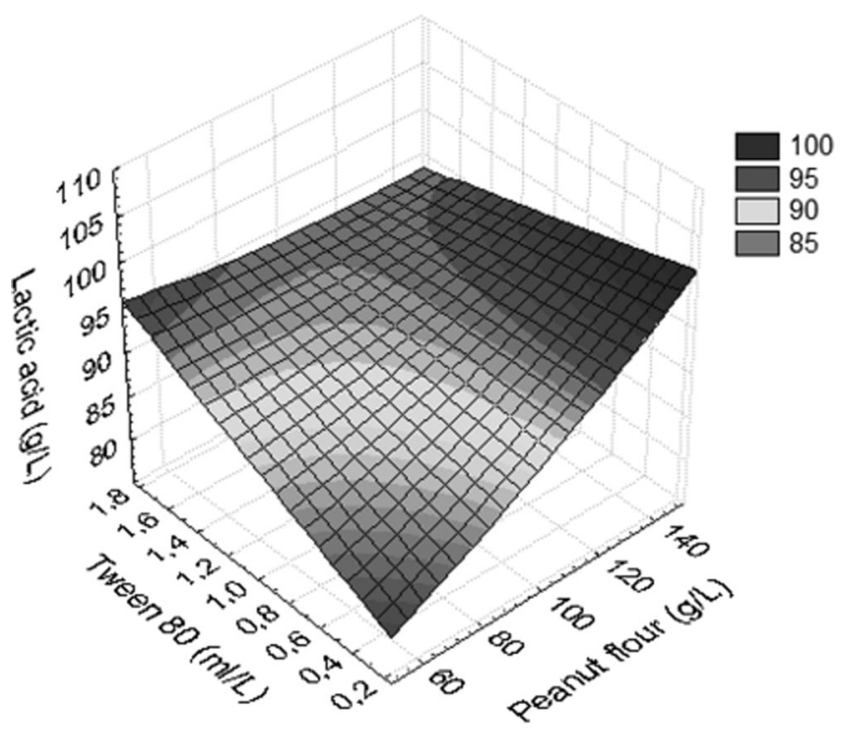

Fig. 4 Response surface for lactic acid production by S. nakayamae showing the interaction between Tween 80 and peanut flour

results were reported by Vasala et al. (2005), who showed that Lactobacillus salivarius ssp. is an ideal organism for lactic acid fermentation in high-salt high-lactose conditions. Additionally, the vitamins and Tween 80 did not significantly influence lactic acid production; nevertheless, it was verified that when the highest concentration of Tween 80 was used, there was higher lactic acid production. However, previous studies reported a positive influence of B vitamins on lactic acid production (Yoo et al. 1997; Altaf et al. 2007).

Considering these results, Tween 80 , commercial sucrose, and peanut flour were selected for use in the RSM.

\section{Response Surface Methodology (RSM)}

Three factors, commercial sucrose, peanut flour, and Tween 80 , were distributed in three levels, and two axial points and four central points were evaluated. The responses measured were $\mathrm{D}(-)$ lactic acid concentration, productivity, yield, and residual sugar after $72 \mathrm{~h}$ of fermentation (Table 8 ). Among the concentration of nutrients evaluated, $130 \mathrm{~g} / \mathrm{L}$ of commercial sucrose, $130 \mathrm{~g} / \mathrm{L}$ of peanut flour, and $1.5 \mathrm{ml} / \mathrm{L}$ of Tween 80 (run 8 ) achieved the highest $\mathrm{D}(-)$ lactic acid production
(101.99 g/L) and productivity (1.42 g/L h), although there was a high concentration of residual sugar $(26.13 \mathrm{~g} / \mathrm{L})$.

The results obtained were fitted to multiple regression analysis to yield the following regression equation:

$$
\begin{aligned}
Y= & 91.62+5.22 X_{1}+2.75 X_{2}+1.12 X_{3}-2.71 X_{1^{2}} \\
& +2.64 X_{1} X_{2}+1.30 X_{1} X_{3}+0.37 X_{2^{2}}-2.08 X_{2} X_{3} \\
& +0.02 X_{3^{2}}
\end{aligned}
$$

in which $\mathrm{Y}$ is the predicted response $(\mathrm{D}(-)$ lactic acid production) and $\mathrm{X} 1, \mathrm{X} 2$, and $\mathrm{X} 3$ are the coded values of the test variables for commercial sucrose, peanut flour, and Tween 80 , respectively.

An ANOVA of the quadratic regression model demonstrated that the model is significant, as determined by Fisher's test (Fcalc (3.81) $>\mathrm{Ft}(3.39))$. It was also determined that the model has a very low probability value $(($ Pmodel $>F)=0.03)$. The fit of the model was checked by the coefficient of determination $\left(\mathrm{R}^{2}\right)$ and multiple correlation coefficients $(\mathrm{R})$. The $\mathrm{R}^{2}$ value $(0.81)$ for the regression equation indicated that the sample variation for lactic acid of $81 \%$ was attributed to the independent variables. In this case, the value of the coefficient of determination indicated that only $19 \%$ of the total variations were not explained by the model. The high $\mathrm{R}$ value (0.90) demonstrated a strong agreement between observed and predicted values. Among the model terms, X1 was significant with a probability of $95 \%$.

The response for the regression equation was plotted in Figs. 2, 3, and 4. The following graphs show the interaction of the variables and the optimum levels of each variable for $\mathrm{D}(-)$ lactic acid production.

Based upon the response surfaces and the values presented in Table 8, run 12 was considered the most appropriate combination for $\mathrm{D}(-)$ lactic acid production. This run consisted of $110 \mathrm{~g} / \mathrm{L}$ of commercial sucrose, $150.40 \mathrm{~g} / \mathrm{L}$ of peanut flour, and $1 \mathrm{~mL} / \mathrm{L}$ of Tween 80 , producing $99.99 \mathrm{~g} / \mathrm{L}$ of $\mathrm{D}(-)$ lactic acid, with a $1.39 \mathrm{~g} / \mathrm{Lh}$ rate of productivity and a low concentration of residual sugar $(10.24 \mathrm{~g} / \mathrm{L})$.

When the highest levels of commercial sucrose and peanut flour were used, it was verified that this condition produced high levels of lactic acid; however, the amount of residual sugar produced was substantial. The same results were verified on
Table 9 Purification parameters of the fermentation media

\begin{tabular}{llll}
\hline Parameters & Lactic acid & Sugar & Protein \\
\hline [Initial solution] $(\mathrm{g} / \mathrm{L})^{*}$ & 88.27 & 13.50 & 13.54 \\
Initial mass $(\mathrm{g})$ & 5.296 & 0.810 & 0.812 \\
[Final solution] $(\mathrm{g} / \mathrm{L})^{* *}$ & 16.85 & 0.06 & 0.00 \\
Final mass $(\mathrm{g})$ & 4.212 & 0.015 & 0.000 \\
Index & Recovery Yield 79\% & sugar removal 98\% & protein removal 100\% \\
\hline
\end{tabular}

* Initial volume $60 \mathrm{~mL}$; ** Final volume $250 \mathrm{~mL}$ 
commercial sucrose and Tween 80 interaction. The response surface between peanut flour and Tween 80 showed that intermediate concentrations of this components did not produce a satisfactory amount of $\mathrm{D}(-)$ lactic acid . Additionally, it was found that low Tween 80 concentrations combined with high peanut flour concentrations showed higher levels of $\mathrm{D}(-)$ lactic acid production.

Previous studies have reported that RSM is an efficient method for the determination of optimized culture conditions for the production of lactic acid (Lima et al. 2011; Coelho et al. 2011a, b). Chaisu et al. (2014) reported, using RSM, the best percentage of inoculum $(8.02 \%)$ and carbon source $(3.82 \%$ of molasses) to lactic acid production $(38.33 \%)$ by Lactobacillus casei $\mathrm{M}-15$ within $24 \mathrm{hr}$ at $37{ }^{\circ} \mathrm{C}$. Bustos et al. 2004 demonstrated the optimization of culture media applying RSM using Lactobacillus coryniformis. The models predicted a maximum $\mathrm{D}(-)$ lactic acid concentration $(58.9 \mathrm{~g} / \mathrm{L})$ at $96 \mathrm{~h}$ using $5 \mathrm{~g}$ corn steep liquor $/ \mathrm{L}, 3.6 \mathrm{~g}$ Yiest Extract/L, and $10 \mathrm{~g}$ Peptone/L. In turn, Lima et al. (2010) through RSM verified that the best results for lactic acid production $(52.37 \mathrm{~g} / \mathrm{L})$ were obtained with $59.64 \mathrm{~g} / \mathrm{L}$ of lactose, $14.55 \mathrm{~g} /$ $\mathrm{L}$ of corn steep liquor, and $5.65 \mathrm{~g} / \mathrm{L}$ of $(\mathrm{NH} 4) 2 \mathrm{SO} 4$, at $39.6{ }^{\circ} \mathrm{C}$ by Lactobacillus sp. LMI8.

\section{Experimental validation}

A low concentration of Tween $80(0.16 \mathrm{~mL} / \mathrm{L})$ combined with $110 \mathrm{~g} / \mathrm{L}$ of commercial sucrose and $150.40 \mathrm{~g} / \mathrm{L}$ of peanut flour induced a higher $\mathrm{D}(-)$ lactic acid production $(112.93 \mathrm{~g} / \mathrm{L})$, productivity $(1.57 \mathrm{~g} / \mathrm{L} . \mathrm{h})$, and yield $(0.98 \mathrm{~g} / \mathrm{g})$ with a reduced residual sucrose concentration $(9.6 \mathrm{~g} / \mathrm{L})$. Compared with conditions utilizing a higher concentration of Tween $80(1.00 \mathrm{~mL} /$ L), low levels of $\mathrm{D}(-)$ lactic acid $(104,38 \mathrm{~g} / \mathrm{L})$, productivity (1, $45 \mathrm{~g} / \mathrm{L} . \mathrm{h})$ and yield $(0,96 \mathrm{~g} / \mathrm{g})$ were presented.

In order to verify the optical purity of lactic acid produced, the optimized culture media was analyzed by HPLC using a chiral column. S. nakayamae produced $98.75 \%$ of $\mathrm{D}(-)$ lactic acid and $1.24 \%$ of $\mathrm{L}(+)$ lactic acid, thus it is considered a homofermentative microorganism.

\section{Purification and recovery of $\mathrm{D}(-)$ lactic acid}

The centrifuged fermentation medium at $\mathrm{pH} 5.0$ was submitted to the purification process, which involved two steps: (1) double filtration on activated carbon and Celite, and (2) the transformation of calcium lactate into lactic acid via cation resin exchange. The purification and recovery assays were performed in duplicate, and the results are expressed as the mean values (Table 9).

$\mathrm{D}(-)$ lactic acid was efficiently recovered from fermentation medium (79\%). Additionally, protein and sugar were efficiently removed (100\% and $98 \%$, respectively). Previous studies have reported similar recovery yields using other purification techniques, such as solvent extraction, multiple-pass distillation, and micellar-enhanced ultrafiltration (Chen et al. 2012; Geanta et al. 2013). Furthermore, it was verified that there was a low ratio of sugar to lactic acid $(0.36 \%)$, which is essential to polymer synthesis for avoiding caramelization.

\section{Conclusions}

In this study, it was found that S. nakayamae is able to produce high levels of $\mathrm{D}(-)$ lactic acid using peanut flour and commercial sucrose as substrates. Experimental design methodology effectively determined the significant nutrients and optimum concentration of medium components. The purification methodology works with inexpensive and reusable reagents. In addition, the high performance of this method of $\mathrm{D}(-)$ lactic acid production utilizing cheap materials will be beneficial for bioplastic technologies. However, to be applied on a large scale in the lactic acid industries, additional well-established research efforts need to conducted.

Acknowledgments We thank the São Paulo Research Foundation (FAPESP), Braskem, and the National Council for Scientific and Technological Development $(\mathrm{CNPq})$ for fellowships and financial support.

\section{References}

Altaf M, Naveena BJ, Reddy G (2007) Use of inexpensive nitrogen sources and starch for L-lactic acid production in anaerobic submerged fermentation. Bioresour Technol 98:498-503

Bozell JJ, Petersen GR (2010) Technology development for the production ofbiobased products from biorefinery carbohydrates. Green Chem 12:539-554

Bustos G, Moldes AB, Alonso JL, Vazquez M (2004) Optimization of Dlactic acid production by Lactobacillus coryniformis using response surface methodology. Food Microbiol 21:143-148

Chaisu K, Charles AL, Guu Y-K, Yen T-B, Chiu C (2014) Optimization Lactic Acid Production from Molasses Renewable Raw Material through Response Surface Methodology with Lactobacillus Casei M-15. APCBEE Proc 8:194-198

Chauhan K, Trivedi U, Patel KC (2006) Application of Response Surface Methodology for Optimization of Lactic Acid Production Using Date Juice. J Microbiol Biotechnol 16:1410-1415

Chauhan K, Trivedi U, Patel KC (2007) Statistical screening of medium components by Plackett-Burman design for lactic acid production by Lactobacillus sp. KCP01 using date juice. Bioresour Technol 98: 98-103

Chen L, Zeng A, Dong H, Li Q, Niu CA (2012) Novel process for recovery and refining of L-lactic acid from fermentation broth. Bioresour Technol 112:280-284

Coelho LF, Lima CJB, Bernardo MP, Contiero J (2011a) D(-) Lactic Acid Production by Leuconostoc mesenteroides B512 Using different carbon and nitrogen sources. Appl Biochem Biotechnol 164: $1160-1171$

Coelho LF, Lima CJB, Rodovalho CM, Bernardo MP, Contiero J (2011b) Lactic acid production by new Lactobacillus plantarum lmism6 
grown in molasses: optimization of medium composition. Braz $\mathrm{J}$ Chem Eng 28:27-36

Djukić-Vuković PA, Mojovic LV, Vukašinović-Sekulić MS, Rakin MB, Nikolić SB, Pejin JD, Bulatovic ML (2012) Effect of different fermentation parameters on L-lactic acid production from liquid distillery stillage. Food Chem 134:1038-1043

Dumbrepatil A, Adsul M, Chaudhari S, Khire J, Gokhale D (2008) Utilization of Molasses Sugar for Lactic Acid Production by Lactobacillus delbrueckii subsp. delbrueckii Mutant Uc-3 in Batch Fermentation. Appl Environ Microbiol 74:333-335

Geanta RM, Ruiz MO, Escudero I (2013) Micellar-enhanced ultrafiltration for the recovery of lactic acid and citric acid from beet molasses with sodium dodecyl sulphate. J Membr Sci 430:11-23

Ghaly AE, Tango NSM, Avery AC (2004) Batch propagation of Lactobacillus helveticus for production of lactic acid from lactose concentrated cheese whey with microaeration and nutrient supplementation. World J Microbiol Biotechnol 20:65-75

González MI, Álvarez S, Riera FA, Álvarez R (2006) Purification of Lactic Acid from Fermentation Mediums by Ion-Exchange Resins. Ind Eng Chem Res 45:3243-3247

Gowdhaman D, Sugumaran KR, Ponnusami V (2012) Optimization of lactic acid production from tea waste by Lactobacillus plantarum MTCC 6161 in solid state fermentation by central composite design. Int J ChemTech Res 4:143-148

Hetényi K, Németh Á, Sevella B (2008) Examination of medium supplementation for lactic acid fermentation. Hung J Ind Chem 36:49-53

Hofvendahl K, Hahn-Hägerdal B (2000) Factors affecting the fermentative lactic acid production from renewable resources. Enzyme Microbiol Technol 26:87-107

John RP, Anisha GS, Nampoothiri KM, Pandey A (2009) Direct lactic acid fermentation: focus on simultaneous saccharification and lactic acid production. Biotechnol Adv 27:145-52

Kim H, Wee Y, Kim J, Yun J, Ryu H (2006) Production of Lactic acid from cheese whey by batch and repeated batch cultures of Lactobacillus sp. RKY2. Appl Biochem Biotechnol 132:694-704

Kitouni M, Oulmi L (2013) Optimization of cultural conditions for lactic acid production by Lactobacillus bulgaricus attc 11842 grown on whey. IJRET 2:487-493

Li H, Mustacchi R, Knowles CJ, Skibar W, Sunderland G, Dalrymple I, Jackman A (2004) An electrokinectic bioreactor: using direct electric current for enhanced lactic acid fermentation and product recovery. Tetrahedron 60:661-665

Lima CJB, Coelho LF, Blanco KC, Contiero J (2009) Response surface optimization of $\mathrm{D}(-)$-lactic acid production by Lactobacillus SMI8 using corn steep liquor and yeast autolysate as an alternative nitrogen source. Afr J Biotechnol 8:5842-5846

Lima CJB, Coelho LF, Contiero J (2010) The use of response surface methodology in optimization of lactic acid production: focus on medium supplementation, temperature and $\mathrm{pH}$ control. Food Technol Biotechnol 48:175-181

Lima CJB, Coelho LF, Contiero J (2011) The use of response surface methodology in optimization of lactic acid production: Focus on medium supplementation, temperature and $\mathrm{pH}$ control. Food Technol Biotechnol 48:175-178
Mandenius CF, Brundin A (2008) Bioprocess Optimization Using Designof-Experiments Methodology. Biotechnol Prog 24:1191-1203

Marinova M, Kyuchoukov G, Albet J, Molinier J, Malmary G (2004) Separation of tartaric and lactic acids by means of solvent extraction. Sep Purif Technol 37:199-207

Mel M, Karim MIA, Salleh MRM, Amin NAM (2008) Optimizing media of Lactobacillus rhamnosus for lactic acid fermentation. J Appl Sci 8:3055-3059

Meng Y, Xue Y, Yu B, Gao C, Ma Y (2012) Efficient production of Llactic acid with high optical purity by alkaliphilic Bacillus sp. WLS20. Bioresour 116:334-339

Naveena BJ, Altaf MD, Bhadriah K, Reddy G (2005) Selection of medium components by Plackett-Burman design for production of $\mathrm{L}(+)$ lactic acid by Lactobacillus amylophilus GV6 in SSF using wheat bran. Bioresour Technol 96:485-490

Ohara H (2003) Biorefinery. Appl Microbiol Biotechnol 62:474-477

Peterson GL (1977) A simplification of the protein assay method of Lowry et al. which is more generally applicable. Anal Biochem 83:346-356

Qin J, Zhao B, Wang X, Wang L, Yu B, Ma Y, Ma C, Tang H, Sun J, Xu P (2009) Non-Sterilized Fermentative Production of Polymer-Grade L-Lactic Acid by a Newly Isolated Thermophilic Strain Bacillus sp. 2-6. Plos ONE 4:1-7

Sanders ME, Morelli L, Tompkins TA (2003) Sporeformers as human probiotics: Bacillus, Sporolactobacillus and Brevibacillus. Compr Rev Food Sci Food Saf 2:101-110

Timbuntam W, Sriroth K, Piyachomkwan K, Tokiwa Y (2008) Application of bipolar electrodialysis on recovery of free lactic acid after simultaneous saccharification and fermentation of cassava starch. Biotechnol Lett 30:1747-1752

Vasala A, Panula J, Neubauer P (2005) Efficient lactic acid production from high salt containing dairy by-products by Lactobacillus salivarius ssp. salicinius with pre-treatment by proteolytic microorganisms. J Biotechnol 117:421-431

Wang L, Zhao B, Li F, Xu K, Ma C, Tao F, Li Q, Xu P (2011) Highly efficient production of D-lactate by Sporolactobacillus sp. CASD with simultaneous enzymatic hydrolysis of peanut meal. Appl Microbiol Biotechnol 89:1009-1017

Wang Y, Hansong Y, Piao C, Lui J, Cai D, Zheng M, Liu J (2015) Medium optimization of $\mathrm{L}(+)$ - lactic acid production by genome shuffled Lactobacillus rhamnosus Lc-F34 from agriculture wastes using statistical tools resources. Environment and Engineering. Taylor \& Francis Group, London

Wee Y-J, Kim J-N, Ryu H-W (2006a) Biotechnological Production of Lactic Acid. Food Technol Biotechnol 44:163-172

Wee YJ, Yun JS, Kim D, Ryu HW (2006b) Batch and repeated batch production of L(+)-lactic acid by Enterococcus faecalis RKY1 using wood hydrolyzate and corn steep liquor. J Ind Microbiol Biotechnol 33:431-435

Yoo I, Chang HN, Lee EG, Chang YK, Moon A (1997) Effect of B vitamin supplemantation on lactic acid production by Lactobacillus casei. J Ferment Bioeng 84:172-175

Zhang ZY, Jin B, Kelly JM (2007) Production of lactic acid and byproducts from waste potato starch by Rhizopus arrhizus: role of nitrogen sources. World J Microbiol Biotechnol 23:229-236 